IRA-International Journal of Management \& Social Sciences

ISSN 2455-2267; Vol.04, Issue 02 (2016)

Pg. no. 423-431

Institute of Research Advances

http://research-advances.org/index.php/RAJMSS

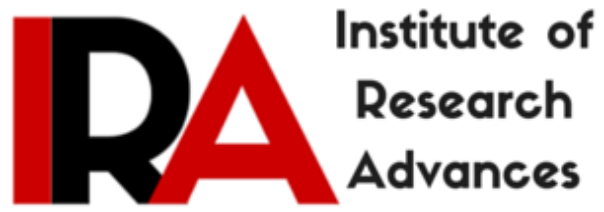

\title{
India Stepping for IFRS: A Critical Review
}

\author{
Dr. Nilmani Tripathi \\ Assistant Professor \\ AMITY College of Commerce \\ Amity University, India.
}

Type of Review: Peer Reviewed.

DOI: http://dx.doi.org/10.21013/jmss.v4.n2.p11

\section{How to cite this paper:}

Tripathi, N. (2016). India Stepping for IFRS: A Critical Review. IRAInternational Journal of Management \& Social Sciences (ISSN 2455-2267), 4(2), 423-431. doi:http://dx.doi.org/10.21013/jmss.v4.n2.p11

(C) Institute of Research Advances

\section{(cc) EY-NC}

This work is licensed under a Creative Commons Attribution-Non Commercial 4.0 International License subject to proper citation to the publication source of the work.

Disclaimer: The scholarly papers as reviewed and published by the Institute of Research Advances (IRA) are the views and opinions of their respective authors and are not the views or opinions of the IRA. The IRA disclaims of any harm or loss caused due to the published content to any party. 


\begin{abstract}
The Asian crisis of 1990, the US accounting scandals like that of Enron, World com, Adelphia, European scandals of Ahold and the present economic crunch all have enforced the importance of effective corporate governance mechanism and global GAAP. All these activities have forced the development of some universal reporting standards i.e. IFRS. The benefits which Indian companies hope to reap after IFRS adoption are numerous. But no benefits can be drawn without facing some crucial challenges. The current shaken market confidence globally may present significant challenges to organizations. Adoption of IFRS could result in an added considerable volatility in reported earnings and some performance specific measures like EPS and P/E Ratio. Entities will have to clarify reasons for this IFRS related volatility apart from other macroeconomic factors. This paper talks about some such challenges and impact of IFRS implementation in some sectors of the Indian economy. The sectors mainly touched upon are that of retail, technology, telecom and power. The paper closes with two small cases of JK Paper and Wipro who have gone for the adoption of IFRS. The cases will aid in understanding the implementation issues of IFRS.
\end{abstract}

\title{
INTRODUCTION
}

The Asian crisis of 1990, the US accounting scandals like that of Enron, Worldcom, Adelphia, European scandals of Ahold and the present economic crunch all have enforced the importance of effective corporate governance mechanism and global GAAP. David Tweedie, the Chairman of International Accounting Standards Board has also said in the Europe Club of Canada on 25 April 2008 that "In the midst of the Asian financial crisis, several companies whose financial statements seemed to indicate that they were secure, suddenly went bankrupt casting great doubt on the veracity of the statements and in particular the national accounting standards in use. While it is important not to overstate the role of accounting standards and practices in precipitating the Asian financial crisis, it is clear that confidence in financial reporting practices in that region disappeared."

Since 2001, the IASB was expected to create a set of principles/ guidelines/ financial reporting standards that may be used globally throughout the world's capital markets. Global markets would work better once we have a single set of high quality global accounting standards The IFRS are an outcome of all the above outrages. They are a principle based framework and not rule based. IFRSs have been proposed by the IASB on topics for which there was no clear cut IAS. Prof. Navin Agrawal in his article ' 3 Ways in which IFRS is a change for the better' has said "IFRS will integrate domestic businesses with the global investor and financial community so that there is no language gap and barrier."

What are IFRS: In a narrow sense IFRS refers to the new numbered series of pronouncements that the IASB has issued, as distinct from the IAS. More broadly, IFRS refers to the entire body of IASB pronouncements, including standards and interpretations approved by the IASB, IASC, and SIC. Till date, IASB has issued 30 IAS and 8 IFRS. It has also issued 11 SICs and 13 IFRICs to provide guidance on some interpretation issues arising from IAS and IFRS. The focus in IFRS is more towards getting the balance sheet right and hence brings significant volatility in the income statement.

Global Adoption of IFRS: Since 2005, the acceptability of IFRS has increased tremendously. More than 100 countries currently are in the process of adopting or planning to adopt a policy of convergence with IFRS so that all entities in these countries speak a common accounting language. Many countries in EU adopted IFRS for the accounting periods beginning on or after 1 January 2005. Approximately 8,000 entities listed in EU are required to follow IFRS in their CFS. All these entities have undergone the conversion exercise from their local GAAP to IFRS. In China alone more than 200 companies have adopted IFRS, although China does not have as long a tradition with modern accounting as India does, but yet it is progressing much faster. Convergence with IFRSs has gained impetus in India too. The Council of the ICAI suggested the adoption of IFRSs at least for listed and other public entities like banks, insurance companies and other large entities from accounting periods commencing on or after $1^{\text {st }}$ April 2011. 
IFRS in India: At the outset it appears that Indian accounting standards are well aligned with IFRSs, but actually they are drastically different in the areas of financial instruments, group accounts, share based payments and business combinations. But even then the benefits which Indian companies hope to reap after IFRS adoption are numerous. Mr V. G. Narayanan, Assistant Professor, Harvard Business School has pointed out that some of the finest implementations of ABC and BSC have been in India. While there are such pockets of excellence, the average firm in India has management accounting systems that are about 10 or 20 years behind what is now state of the art. Indian accounting standards are fairly closely aligned with IFRS. So the switch to IFRS will be fairly easy. The potential benefits for us are immense. Practically foreign investors are more likely to invest in firms whose accounting is similar to accounting of the country of the investors. Thus we can attract more foreign capital, lower the cost of capital for our firms and increase job opportunities for Indian accountants by adopting IFRS.

Besides, the eventual adoption of IFRS by all countries appears inevitable. Early adoption of IFRS will give an opportunity to shape it. If we are one of the last to join the bandwagon, we will not have any real opportunity to influence and shape the setting of international accounting standards. Since this window of opportunity will pass fairly soon, we need the Indian industry, government, and the accounting profession to move quickly towards adopting IFRS.

A study conducted by CFO Research Services for ACCA, the global body for professional accountants, polled finance executives in India as part of a survey of 792 senior executives around the world. 41 percent of the 94 Indian CFOs, directors of finance, and other executives surveyed said the regulators should move even sooner because China and other global competitors have already effectively switched over to IFRS.

Planned Adoption of IFRS in India

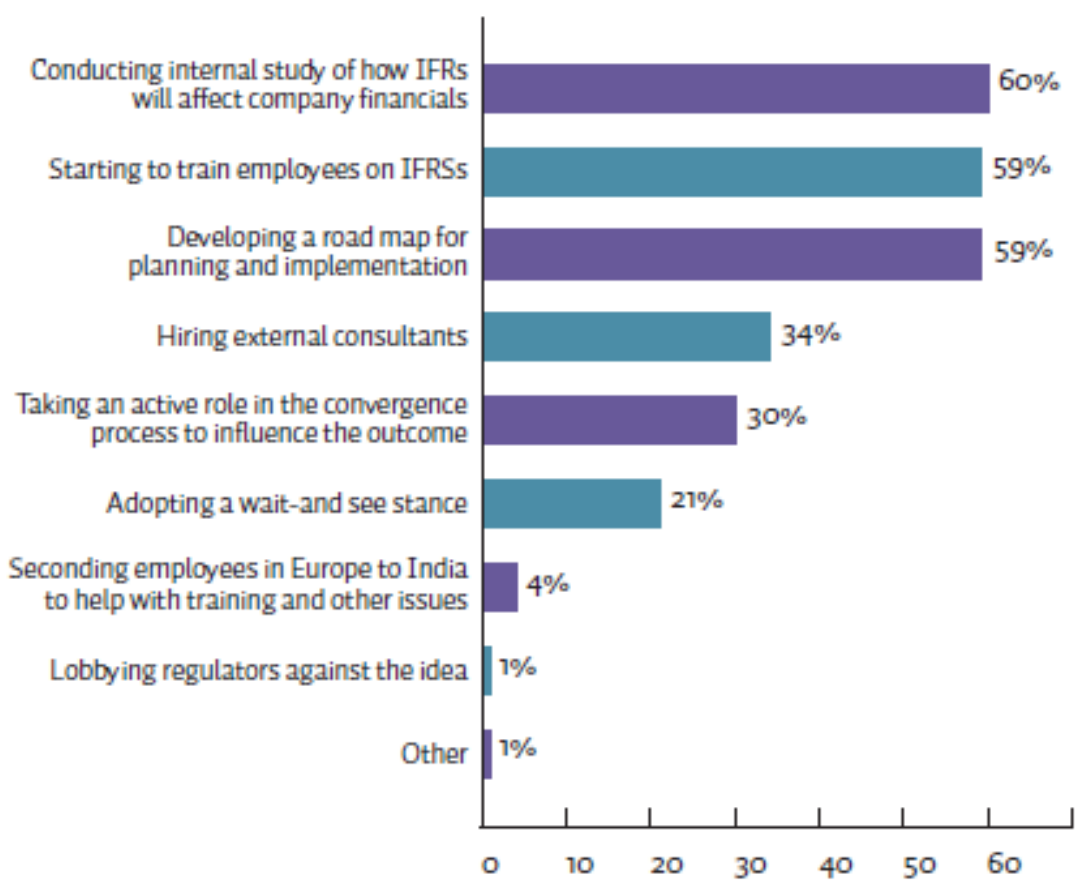

Source:- CFO Report- Oct-2008 
Benefits of IFRS Adoption: Some major benefits of adopting IFRS are:-

$>\quad$ IFRS compliant financial statements would enhance international comparability of accounts

$>\quad$ set a reliable framework for users of financial statements

$>\quad$ help cross border capital listing

$>\quad$ Enable benchmarking with global peers and improve brand value.

$>\quad$ Improved Access to International Capital Markets

$>\quad$ Lower Cost of Capital

$>\quad$ Enable Benchmarking with Global Peers and Improve Brand Value

$>\quad$ Escape Multiple Reporting

$>\quad$ Reflects True Value of Acquisitions

The Adoption Dilemma This is a period of mild economic conditions. The current shaken market confidence globally may present significant challenges to organizations. Adoption of IFRS could result in an added considerable volatility in reported earnings and some performance specific measures like EPS and P/E Ratio. Entities will have to clarify reasons for this IFRS related volatility apart from other macroeconomic factors. Some entities may completely be wiped off of their retained earnings while for some it may add on to their retained earnings.

Nations around the world are faced with the dilemma of whether their national accounting standards should be aligned to IFRS or take the big bang approach of adopting IFRS as written by IASB and follow standards that are globally applied irrespective of the economic environment. This creates a problem that IFRS with modifications by various countries would result in multiple and probably inconsistent versions of IFRSs globally. This becomes IFRS as applied by a specific country as opposed to IFRS as issued by IASB. This actually would defeat the very purpose of global convergence, which is to move toward a single set of high-quality accounting standards for use throughout the world.

Difficulties in India: Though IFRS has been written with the intention of global application, we will have to evaluate their viability under the Indian economic environment such that deviations are few and rare. Vandana Saxena Poria, CEO of Get Through Guides (GTG), a leading accountancy training provider, feels finance executives may be underestimating the level of preparation required.

When Indian entities will implement IFRS, the roadmap needs to be very comprehensive because the difficulties would be manifold due to numerous reasons. Out of the 38 effective IFRS standards, there are only 2 standards in India that have no difference with IFRS and six have minor differences. Eighteen standards of IFRS will need a level of technical preparedness by the industry and the professionals for implementation or would have conceptual differences with the Indian standards. Ten standards need changes in laws and regulations for them to comply with the principles of IFRS. There have to be significant amendments in various regulations and acts like that of the Companies Act, RBI Act, tax laws, laws for specialised industries including banking, insurance etc, for compliance with IFRS principles.

So the major challenges that Indian entities will have to deal with may be as follows:

$>$ Scarce knowledge, resources and literature about IFRS

$>$ Lack of adequate valuation models and skills

$>$ Lack of professional making reliable fair value estimates

$>$ Insufficient data for the valuers to perform valuation

$>$ Regulatory requirements may continue to require different accounting treatment as compared to IFRS, such as in the case of tax accounts

$>$ Incapable Information system

$>$ Heavy cost involved

$>$ Unique Circumstances of SME's not considered

$>$ Communicating change in business parameters due to use of fare values

$>$ Computation of distributable profit considering unrealized gain \& losses 
Still, India's road to IFRS is long \& could be rocky. Internally, companies appear to be doing sensible preparatory work, but there is still no clarity on the external front, particularly amendments to legislation and regulatory frameworks. "Here in India, the format and certain aspects of financial reporting are governed by various regulations like the Companies Act, Reserve Bank of India regulations, Banking Regulations Act, and the Insurance Act," says Wipro's Arunachalam. "How will you take that power away from those laws and put it in the hands of the standard-setting process? We need to deal with these regulatory issues [if we want to] achieve convergence."

Impact on Some Key Industries in India: Here we would like to deal with some critical issues involved in IFRS adoption in some key Indian industries:

Retail: The treatment of capitalization of refurbishment cost of existing stores is different in case of GAAP and IFRS. In Indian GAAP the cost of construction, painting, false ceiling, furnishing etc., of existing stores, is capitalized to the extent that it increases the future economic benefits in excess of the original assessed standard of performance. The cost of overhaul that does not increase the benefit beyond the originally assessed standard of performance is not capitalized. For eg, the management of a retail chain may have a policy to carry out major refurbishments at regular interval of 2 years. Such expenditure under existing AS 10 cannot be capitalised. Under IFRS retail entities will have to identify cost of refurbishment and major overhauls as a separate component and capitalize such cost which is amortized over the period when the next overhaul is expected.

Similarly, the expenditure during the development period of the store like that of renovation, construction or even staff costs will have to be dealt with differently. The cost of construction, painting, false ceiling, furnishing, etc. would be capitalized. However the cost of the staff is not capitalized as it is not necessary for bringing the asset to its working condition and hence should be expensed. Whilst this is true for both IFRS and Indian GAAP, in practice, some companies may have interpreted Indian GAAP as allowing capitalization.

Another issue is that of leasing arrangements. Normally, retail entities pay rentals based on revenue or profit generated by them from that outlet or premises. Indian GAAP does not prescribe any specific accounting treatment for derivatives. Under IFRS, such contracts will have to be analyzed to identify any embedded derivative, which requires separate accounting.

Under Indian GAAP and IFRS, initial direct costs are capitalized if the lease is classified as finance lease. There is no specific accounting treatment specified for costs if the lease is classified as operating lease under IFRS and Indian GAAP. For Indian GAAP, the EAC has opined that straightlining would be required for operating leases. Under IFRS the final verdict is not yet known.

Technology: The nature of technology entities is such that significant accounting challenges arise in the areas of software revenue recognition, accounting for intangible assets and ESOP. Moreover companies in India are more exposed than others to foreign currency variations as they generate significant revenues from export of services. Here we will have a glance at the challenges that arise in this sector due to the conversion to IFRS.

One issue is that of the timing revenue recognition. Another matter is of accounting for multiple element contracts like complete business solution through SAP which includes delivery of hardware, SAP license fee, implementation consultation charges, maintenance charges etc. No specific guidelines are available in AS 9 on accounting for such contracts. Moreover, multiple element contracts that provide for free "version upgrades" and other "free" add on software/hardware are generally treated as being "free" and are not fair valued to be accounted for separately over the period of the contract. These issues have not been addressed in IFRS also. IAS 18 provides limited guidance with respect to multiple element contracts. 
As per the global trend, Indian companies are also offering various ESOP schemes to the employees. The valuation of these benefits is done based on the intrinsic value method. But with the adoption of the IFRS the Fair Value Methods will have to be undertaken which may reduce the profits.

One another issue is that of outsourcing contracts for programming support, data storage, network support etc. These arrangements are normally structured as service contracts but under IFRS they will have to be treated as lease arrangements hence a different accounting treatment. If such arrangement is identified as a leasing arrangement, revenue and asset under consideration will be accounted as per principles of IAS 17 Leases.

To manage the exchange fluctuation risk, technology entities use various risk management products, such as forward exchange contracts, options and swaps for hedging the exchange rate fluctuations. Presently, Indian GAAP provides guidance for forward contracts only. Based on this guidance, entities treat forward exchange contracts for hedging purpose without having robust documentation. Under IFRS all derivatives are required to be recognised in the financial statements at fair value. Hedge accounting is permitted only if entities have robust documentation and specified conditions are satisfied. Thus, entities will have to reconsider their hedging strategies and documentation protocols.

Telecom: Telecom entities provide package offers comprising handset, prepaid minutes, messages, discounts, special offers and other incentives. The accounting procedures will have strong impacts on the revenue and results. For example, separating handset sales from connection revenues may result in increased revenues upfront for sale of handsets. Indian GAAP does not provide any specific guidance on revenue recognition in case of multiple element contracts and hence inconsistent practices are followed by various telecom entities. The recognition criteria are applied to two or more transactions together when they are linked in such a way that the commercial effect cannot be understood without reference to the series of transactions as a whole.

The key issue which all telecom entities will have to face on adoption of IFRS is whether the components of a single transaction can be technically and commercially separated, and if yes, whether the fair values can be reliably determined to recognise revenue. As no specific guidance is available under IFRS, many entities could well use the hierarchy in IAS 8 to consider any relevant US GAAP requirement for determining fair value of separate components.

In the Telecom Industry, entities often buy and sell capacity of each other's networks, often referred to as Indefeasible Right to Use (IRU). If it is considered that an IRU arrangement contains a lease then the appropriate arrangement under IFRS would be determined by IAS 17 Leases. IFRIC 4 provides more guidance on this subject. Under Indian GAAP no guidance is available on identification of leases contained in arrangements or transactions which are not structured as lease. Thus, lease elements contained in IRU may not be captured by AS 19, which governs lease accounting in India. The accounting for

IRU under Indian GAAP is significantly different from that required under IFRS.

It is common for telecommunications operators to enter into arrangements with third party content providers to offer a range of services to their subscribers (e.g., ringtones, games and traffic updates), with charges based either on duration or on quantity. Close attention needs to be paid to the details of each such arrangement since that may have an impact on the accounting.

In the construction of networks, mobile and fixed line operators often build assets on leased land or premises where an obligation exists (e.g., under the lease agreement) to reinstate the land or premises at the end of the agreed term. Provision for such costs is required under IFRS where they are referred to as ARO. The obligation is accounted for by including the present value of the estimated cost of dismantling and removing the asset as part of the cost of the asset and setting up a provision for an equivalent amount. The discounting of provisions get unwound over the relevant period and is 
accounted for as interest expense. The challenge in providing for ARO is that often it may not be evident from the contractual terms that an obligation exists. The contract may be unclear or silent on restoration requirements at the end of the contracted period. There might not be express legislation, which requires companies to carry out restoration work. In such cases entities need to make their 'best estimate' based on past experience.

Another complexity in ARO provision, under IFRS, is the assumption of tenor of lease. In these circumstances, issues arise in calculating the present value of ARO. Should the obligation be based on the original length of the lease or the extended period?

Ernst \& Young developed and disseminated an online survey on changing reporting and regulatory requirements in the telecom sector. The study brought out the following points:

» Increasing customer demands for new communication products and services are pressuring telecom entities to update existing networks or deploy new ones

» Many telecom entities are yet to recognise the need to proactively manage potential changes to their fixed asset accounting practices and how this impacts their competitive position

» Matching operational realities to changing business and customer demands and complying with IFRS are critical to success in the telecommunications marketplace

» The financial health of the industry was stabilising, opening the path to renewed profitability and growth, however, the transition to IFRS may create earnings volatility

» The entities that succeed in a dynamic environment will be those that can adapt to IFRS quickly while proactively managing their asset bases

» The pressure to update or replace network assets increases the risk of traditional assets being impaired. In the study referred above, $62 \%$ respondents believed that their current IT systems, accounting processes and fixed asset designs were suitable for IFRS adoption.

In the case of Telecom entities, IFRS reporting requirements will have the greatest potential impact on the management of their fixed asset accounting-component accounting, estimation of useful life, residual value, impairment, etc.

Power: The power industry operates in a highly regulated environment and is highly capital intensive. The critical activities involved are fuel sourcing, generation, transmission and distribution all of which involve accounting and hence IFRS related issues.

These entities are involved in long term purchase contracts for oil, gas, coal and/or power for an uninterrupted supply but then have to face huge problems of volatility in the international exchange market. In such cases, the contracts may meet the definition of a derivative i.e hedging from exchange volatility is possible. In Indian GAAP such derivatives are not required to be recognized. Under IFRS it will have to be fair valued. Clearly long term fuel purchase contracts that are fair valued may significantly increase income statement volatility.

Utility units are capital intensive. An in-depth analysis is required to identify significant components that make up a plant or a grid. The optimum life for each component is not similar. For eg. A boiler is exposed to great heat so lesser life, whereas the life of the transformer may be longer. These components need to be depreciated over their own useful lives, rather than the life of the asset as a whole. The application of the components approach in this industry is a challenging task as it requires technical knowledge that usually cannot be provided by the accounting department on its own. Experience of IFRS implementation elsewhere in the world indicates that there is considerable disparity in the way in which components were identified for power plants.

In India various entities enter into power purchase agreements to fulfil their energy demand. Also, many utility entities enter into a contractual arrangement conveying the right to use a part of its grid to third parties. Such contracts are normally accounted as sales/service contracts in Indian GAAP. On transition to IFRS, such an arrangement needs to be analysed to identify whether it contains a 
lease. This can have significant implications on the balance sheet of power entities as an asset under consideration may have to be derecognised if the arrangement is assessed as finance lease.

\section{Present Scenario:}

Recently India has experienced tremendous growth and increased engagement with, and influence on, the world economy. In accordance with this many organizations have already started taking initial actions for the early and quick adoption of IFRS. A few have conducted internal studies of how IFRS will affect their financials, while some have planned to develop a road map for planning and implementation, and will start training employees on the standards. Only a few are taking a wait-andsee attitude. Get Through Guides (GTG) is already training a number of audit firms and multinational companies in India on IFRS.

JK Paper Case: India's largest producer of branded paper products and operator of two paper mills, the first in Indian paper industry to win ISO 14000 certification, has a large environmental footprint. As a good corporate citizen, the company keeps up to its stakeholders expectations and so has also started preparing to switch over its financial reporting patterns to IFRS. "It makes it more acceptable to international investors if our accounts are stated according to international standards," says Kumaraswamy. "There will be a benefit in terms of how we are seen. And if we want to access more funds from abroad for new growth aspirations, it will definitely help us." But Kumaraswamy expects that "the disturbance might be a one-time off affair, rather than a continuing source of worry." As a manufacturing company, JK Paper does not carry derivatives and other financial assets on its books as a bank or insurance company might. It does have factories and equipment, but since impairment is already part of Indian accounting standards, the company has been providing for impairment in its financial statements. "Even the initial impact may not be that much in our case," Kumaraswamy says. To get a better handle on the impact, he has launched a quantification study of the effects of IFRS on the company's accounts.

WiproCase: Wipro Technologies is much ahead of its counterparts traveling the road of IFRS adoption. The IT services giant, listed in New York 8 years back, had thus reconciled its financial reporting under Indian GAAP with the more complicated US GAAP. They thus have an experience of managing this type of a complexity. Satish Arunachalam who heads the company's financial reporting function says "“'In technical terms, in the understanding of the literature and the application, I think we are fairly comfortable, so I would say we are 90 percent ready to do that," says Arunachalam. "But we have [some way to go] in terms of operational implementation."

After looking over the training materials offered by the ICAI, Wipro plans to come to an agreement with the institute for a corporation-wide training program. Arunachalam wants an "India-oriented training module" that is programmed to identify issues in the Indian context. Going forward, he thinks the bigger issue is making sure that the accounting professional course curriculum is overhauled to give fresh recruits the necessary grounding in IFRS. "Plus, moving to IFRS will exert some kind of requirement on the IT infrastructure and other systems as well," he says.

Conclusion: There is still a long way to go. We need all the stakeholders — the industry, ICAI, government, RBI, SEBI, tax authorities and other regulators to fit into place in the transition process to IFRS. The discussion we need to engage is to holistically review the appropriateness of every application for India and address such issues in the transition provisions including those relating to first time adoption. The thought behind actions needs to be clearly articulated and debated.

\section{References}

1. D. Murali ; India must adopt IFRS right away' Business Line Thursday, Jan 04, 2007

2. http://profit.ndtv.com/ Full convergence with IFRS to benefit Indian firms

3. The Economic Times IFRS: The impact on Indian corporates 7 Jul, 2008, Richard Rekhy 
4. http://www.business-standard.com visited on $15^{\text {th }}$ September 2008; Kaushik Dutta: Bridging the GAAP

5. www.cainindia.org visited on $25^{\text {th }}$ Oct. 2008

6. http://www.livemint.com visited on $15^{\text {th }}$ Oct. 2008; Prof Agarwal Navin; "IFRS 3 ways in which is a change for the better" 